\section{P-41 WHAT THE MEN SAY: MEN'S SPACE: DEVELOPING A GROUP FOR MEN, RUN BY MEN}

Sarah Popplestone-Helm, Matt Jackson. St Richard's Hospice, Worcester, UK

\subsection{6/bmjspcare-2018-hospiceabs.66}

Engaging in group work is challenging. Men with a palliative diagnosis can be reticent to accept group support. This abstract introduces a group of men with a palliative diagnosis who want to tell their story. The group meets at their local hospice's, 'Men's Space'.

It was slow to start but they developed a close bond, an ethos of care, support and a sense of fun. They wanted to break down barriers and expel myths to encourage other men to join. The group planned and held a day to encourage new members. As numbers grew, they engaged in gardening, painting and other activities. They welcomed speakers including a Para-Olympian. Supported by the family support and hospice nursing teams they toured local factories, met with a premiership rugby team and a National League basket-ball team. They are currently engaged in developing a calendar of their experiences together to raise funds for the hospice. Local businesses provided them with a summer house to meet in, and a greenhouse in which they produce vegetables for the hospice kitchen, for themselves and their families.

It is difficult when group members die, but the group has developed ways of remembering each other, they talk openly about what they want from each other as their own deaths approach. This self-directed group is passionate and articulate, willing to speak at national level to ensure longevity for the men who come after them. They have made videos for the hospice website. Met with the local commissioning group and talked to external hospital groups to encourage others to join Men's Space or to set up something similar.

What the men say:

'I love to sit and listen to the banter around the table.'

'It gives me the confidence to keep going when things are looking bleak.'

\section{P-42 AN INNOVATIVE APPROACH TO TRANSFORM END OF LIFE CARE IN A PRISON SETTING}

Derek Hart, Martin Thomas, Liz Lawley. St Luke's Hospice, Plymouth, UK

10.1136/bmjspcare-2018-hospiceabs.67

Since the End of Life Care Strategy (Department of Health, 2008) stated that high quality services should be available in all locations, including prisons, there has been recognition of the increasing demand for end of life care within UK prisons as their population ages, presenting both practical and emotional care challenges (Turner, 2018). Inequities in palliative care provision for prisoners as opposed to the general population have been highlighted (Fletcher, Payne, Waterman et al., 2013; Prisons and Probation Ombudsman, 2017).

Despite hospice clinical nurse specialist (CNS) involvement in providing end of life care within the local category $\mathrm{C}$ prison, joint working between the hospice CNS and the prison matron identified the need to improve access to and choice in end of life care. Referral rates for palliative care support were low and restricted to those with cancer, minimal advance care planning (ACP) and support was in place and prisoners were being transferred to another prison with palliative care beds for last days of life care. Burdett funding was obtained for a one-year project to address this.

Through a process of consultation and dialogue with prison management and healthcare staff, specific changes were made to end of life care provision within the prison including an end of life education programme for prison staff, monthly multi-disciplinary meetings to identify those at end of life, introduction of in-reach clinics and cell visits and improved access to out-of-hours teams, end of life services and as needed medication for symptom control.

In the year following completion of the project, referrals to the palliative care team doubled and included non-malignant conditions such as end stage respiratory disease. Prison staff reported more compassionate and positive attitudes and understanding of end of life care issues amongst staff and inmates, with ACP and identification of preferred place of care becoming embedded within the culture of the prison. This has allowed individuals to receive last days of life care within the prison.

\section{P-43 PALLIATIVE CARE FOR PRISONERS: A PARTNERSHIP APPROACH}

${ }^{1}$ Rachel Kemp, ${ }^{1}$ Libby Milton, ${ }^{2}$ Gerald Michie, ${ }^{3}$ Angela Wotherspoon. ${ }^{1}$ Marie Curie Hospice, Edinburgh, UK; ${ }^{2}$ Scottish Prison Service, Edinburgh, UK; ${ }^{3} \mathrm{NHS}$ Lothian, Edinburgh, UK

\subsection{6/bmjspcare-2018-hospiceabs.68}

Background Supporting our hospice Widening Access agenda, we have developed a partnership with our local prison, HMP Edinburgh. With one of the highest populations of older, long term prisoners in Scotland, there are specific challenges to ensure high quality palliative and end of life care for this group. Barriers include: Identification of prisoners with palliative care needs; Lack of 24/7 health care; Timely access to medication; Prison environment and regime; Staff confidence and competence; Some high risk offenders may not be eligible for compassionate release.

Aim To transform the experience of palliative care for prisoners through a partnership approach with prison, health and palliative care staff, by:

- Proactive identification of those with palliative care needs

- Appropriate assessment and management plans

- Planning ahead to ensure palliative care needs can be safely and effectively met in the hospice or the prison

- Support for staff

- Address barriers to providing end of life care

- Access to medication

- Out of hours health and social care support.

Approaches Clinical: Hospice clinical nurse specialist attendance at monthly prison healthcare meetings; Individualised review and plans for each prisoner with palliative care needs.

Educational: Hospice staff delivery of 'toolbox' talks for prison staff; Identification of link staff at each site.

Cultural shift: Build relationships and nurture understanding in both hospice and prison setting; Hospice staff visits to prison with reflective learning sessions; Quarterly strategic meetings with hospice, Marie Curie Nursing Service, NHS and Scottish Prison Service to continue partnership working. 


\section{Outcomes}

- Hospice staff attend prison palliative care meeting

- Prisoners with complex needs referred to specialist service

- Plans in development to access out of hours nursing care and medication

- Commitment to ongoing development work

- Hospice staff supportive and confident to look after prisoners

- Partnership with prison viewed by charity as an opportunity not a threat.

\section{\begin{tabular}{|l|l}
\hline P-44 THE DYING WELL IN CUSTODY CHARTER: EXPERIENCE \\
\hline
\end{tabular} OF HMP LITTLEHEY AS A PILOT SITE}

${ }^{1,2}$ Annelise Matthews, ${ }^{3}$ Maria O'Neill, ${ }^{3}$ Nigel Jones. ' ${ }^{3}$ ue Ryder St John's Hospice, Bedford, UK; ${ }^{2}$ North West Anglia NHS Trust, Huntingdon, UK; ${ }^{3} H M P$ Littlehey, Huntingdon, UK

\subsection{6/bmjspcare-2018-hospiceabs.69}

Background The number of prisoners over 50 years old has nearly trebled in the past 15 years, leading to an inevitable increase in natural deaths in prisons. The number of expected deaths has more than doubled (Prisons and Probation Ombudsman, 2017). The Dying Well in Custody Charter Self Assessment Tool was launched in March 2018 to promote good practice in palliative and end of life care in prisons (Community of Practice for Prisons Steering Group, 2018). It includes eight ambition statements, each with quality statements and evidence guides and is backed by NHS England Ambitions for Palliative and End of Life Care Partnership (Community of Practice for Prisons Steering Group, 2018).

HMP Littlehey is a Category C prison. With approximately 1220 residents, it is one of England's largest older age prisons: $35.5 \%$ aged over 50 years and $6.6 \%$ over 70 . The prison has no 24 hour healthcare but has developed close links with its local palliative care team and hospice.

Aims To promote quality palliative care for prisoners by piloting the Dying Well in Custody Charter and sharing the experience.

Methods A multi-disciplinary group of a nurse, a governor and a palliative medicine consultant used the Self Assessment Tool to review current work.

Results The tool enabled a review of current practice and establishment of standards including:

- Identification of patients using the SPICT for All tool (University of Edinburgh, 2018)

- All patients enabled to do Advance Care Planning

- All patients having a Family Liaison Officer and keyworker

- Establishment of Palliative Care MDT

- Controlled Drugs available via locked box in cell subject to risk assessment

- Timely application for compassionate release

- Timely assessment by specialist palliative care

- Healthcare input into risk assessments on restraint.

Conclusions The Self Assessment Tool is a helpful way to evidence existing good practice. It may also be useful where change is required, or palliative care is infrequent in demonstrating the standards expected in the prison service and which can be achieved.

\section{P-45 COLLABORATIVE SPECIALIST PALLIATIVE CARE BEDS}

${ }^{1}$ Ross Chirgwin, ${ }^{1}$ Nichole Hockett, ${ }^{1}$ Niamh Eve, ${ }^{2}$ Luan Jimack. ${ }^{1}$ St Helena Hospice, Colchester, UK; ${ }^{2}$ Anglia Community Enterprise, Clacton on Sea, UK

10.1136/bmjspcare-2018-hospiceabs.70

Background Our hospice covers a geographical area with a high elderly population in both affluent and deprived areas (Sleeman, Davies, Verne et al., 2016). Residents living in deprivation are less likely to have access to palliative care services (Care Quality Commission, 2016). Local data shows that $16 \%$ of patients in 2017 choose hospice as their preferred place of care (PPC) but only $4.5 \%$ of annual deaths in our locality occur in the hospice.

Aims Tendring residents theoretically have equal access to hospice beds but local data demonstrates that they are half as likely to die in a hospice than residents in Colchester. This suggests an inequality in provision and unmet need in the Tendring area (Help the Hospices, 2013). In order to address this shortfall, our hospice and the local community provider have worked in collaboration to provide additional specialist end of life care beds.

Method Patients are admitted to the community hospital nurse-led unit where we aim to provide high quality, holistic care. Patients are admitted either from the community or transferred from the local acute hospital. Day to day care provision is provided by the nursing staff on the ward with support being provided daily by hospice clinical nurse specialists (CNSs). By working in collaboration residents are offered the choice of a local community hospital as their PPC to allow them to be cared for closer to home. The CNSs have also provided formal training to the multidisciplinary team.

Results Since September 201753 patients have benefitted from this service which has provided additional access to local community beds with support from a specialist palliative care team. Collaborative working has enabled adequate symptom control, appropriately supported discharges or a peaceful death to achieve their PPC.

Conclusion This collaborative service has enabled access to additional specialist palliative care beds and supported patients to achieve their preferred place of care.

\section{P-46 ACCESS TO SPECIALIST PALLIATIVE CARE - A HEALTH EQUITY AUDIT}

${ }^{1}$ Judith Shankleman, ${ }^{2}$ Margaret Clifford, ${ }^{2}$ Jane Naismith. 'London Borough of Tower Hamlets, London, UK; ${ }^{2}$ St Joseph's Hospice, London, UK

10.1136/bmjspcare-2018-hospiceabs.71

Provision of palliative care based solely on need is the core business of all specialist palliative care (SPC) services. This audit aims to identify inequities in access to hospice-based SPC in a deprived and ethnically diverse borough of London. Characteristics of those who died between 2010 and 2015 who were known to the hospice were compared with population deaths over the same period. Between 2010 and 2015, the number of deaths remained stable (av. 1013) while the number of residents who used SPC services increased from 359 to 525 . Only $11 \%$ male $/ 16 \%$ female deaths known to 